\title{
Optimization of surface integrity in dry hard turning using RSM
}

\author{
SUHA K SHIHAB*, ZAHID A KHAN, AAS MOHAMMAD and \\ ARSHAD NOOR SIDDIQUEE
}
Department of Mechanical Engineering, Jamia Millia Islamia (A Central University), New Delhi 110 025, India
e-mail: suhakarim_10@yahoo.com; zakhanusm@yahoo.com;
amohammad1@jmi.ac.in; arshadnsiddiqui@yahoo.com

MS received 24 March 2013; revised 16 December 2013; accepted 21 April 2014

\begin{abstract}
This paper investigates the effect of different cutting parameters (cutting speed, feed rate, and depth of cut) on surface integrity defined in terms of surface roughness and microhardness in dry hard turning process. The workpiece material used was hardened alloy steel AISI 52100 and it was machined on a CNC lathe with coated carbide tool under different settings of cutting parameters. Three cutting parameters each at three levels were considered in the study. Central composite design (CCD) of experiment was used to collect experimental data for surface roughness and microhardness. Statistical analysis of variance (ANOVA) was performed to determine significance of the cutting parameters. The results were analysed using an effective procedure of response surface methodology (RSM) to determine optimal values of cutting parameters. Several diagnostic tests were also performed to check the validity of assumptions. The results indicated that feed rate is the dominant factor affecting the surface roughness whereas the cutting speed is found to be the dominant factor affecting the microhardness. Results also revealed that within the range investigated, good surface integrity is achieved when feed rate and depth of cut are near their low levels and cutting speed is at high level. Finally, the optimal cutting parameters and model equations to predict the surface roughness and microhardness are proposed.
\end{abstract}

Keywords. Hard turning; surface roughness; microhardness; RSM.

\section{Introduction}

Machining of hardened steels ( $>45 \mathrm{HRC}$ ) using single point turning, commonly referred to as hard turning, is of considerable interest to manufacturers of ball bearings, and other mechanical

*For correspondence 
power transmission components. Bearing steels (e.g., AISI 52100) are the most common examples of these materials, which are conventionally finished by grinding (Diniz et al 2003; Ramesh et al 2005; Umbrello et al 2008; Paiva et al 2009; Thiele \& Melkote 1999). Hard turning is generally used as a substitute to grinding for performing finishing operations for hardened steel. Turning of hard steel using advanced tool materials like coated carbide, mixed ceramic and cubic boron nitride has advantages such as short cycle time, process flexibility, compatible surface roughness, higher material removal rate, ability to machine thin wall sections, and less environment problems without the use of cutting fluid as compared to grinding or polishing (Benga \& Abrao 2003; Suresh et al 2012; Khan et al 2009; Gaitonde et al 2009; Aslan et al 2007; Davim \& Figueira 2007; Diniz \& Oliveira 2004; Kumar \& Durai 2003). The hard turning can offer a reasonably high accuracy for the hardened components, but the major problems occur with surface quality. The surface integrity is often of great concern due to its impact on the product quality. It is well-known that the machined surface characteristics are important in determining the functional performance such as fatigue strength, corrosion resistance and tribological properties of machined components. Often, the major indication of surface integrity is surface roughness. However, the material microhardness also changes in machined-hardened steels, and it must be taken into account for improving product performance. Therefore, several researchers experimentally investigated relationships between machining parameters and the surface integrity (surface roughness, hardness) during hard turning (Krishna et al 2010; Thakur et al 2009; Tzeng et al 2009; Sahin \& Motorcu 2008; Sharma et al 2008; Manna \& Salodkar 2008; Kumar \& Ramamoorthy 2007; Morea et al 2006; Grzesik \& Wanat 2006; Ezugwu et al 2005; Risbood et al 2003; Dhar et al 2002; Isik 2007; Khan et al 2009).

\section{Experimental details}

Hard turning of AISI 52100 hardened alloy steel without using coolant (dry condition) was carried out on CNC lathe machine. The chemical composition of AISI 52100 is shown in table 1. The cutting parameters and their levels used in hard turning are shown in table 2. CNMG 120408TN7105 coated carbide insert ( $\mathrm{TiN}-\mathrm{TiCN}-\mathrm{AL}_{2} \mathrm{O}_{3}-\mathrm{TiN}$ ) having nose radius of $0.8 \mathrm{~mm}$ was used as cutting tool. The surface roughness tester (model: SURFTEST, SV-2100; make: Mitutoyo,

Table 1. Chemical composition (wt \%) of work material AISI 52100 Alloy steel.

\begin{tabular}{cccccccccc}
\hline $\mathrm{C}$ & $\mathrm{Si}$ & $\mathrm{Mn}$ & $\mathrm{S}$ & $\mathrm{P}$ & $\mathrm{Ni}$ & $\mathrm{Cr}$ & $\mathrm{Mo}$ & $\mathrm{Cu}$ & $\mathrm{Fe}$ \\
\hline 0.98 & 0.28 & 0.39 & 0.024 & 0.023 & 0.141 & 1.302 & 0.081 & 0.042 & Balance \\
\hline
\end{tabular}

Table 2. Cutting parameters and their levels.

\begin{tabular}{lclccc}
\hline Factor & Symbol & Unit & Level-1 & Level-2 & Level-3 \\
\hline Cutting speed & $A$ & $\mathrm{~m} / \mathrm{min}$ & 100 & 175 & 250 \\
Feed rate & $B$ & $\mathrm{~mm} / \mathrm{rev}$ & 0.1 & 0.16 & 0.22 \\
Depth of cut & $C$ & $\mathrm{~mm}$ & 0.2 & 0.6 & 1 \\
\hline
\end{tabular}


Table 3. Experimental results of surface roughness and microhardness.

\begin{tabular}{lccccc}
\hline Run & $A \mathrm{~m} / \mathrm{min}$ & $B \mathrm{~mm} / \mathrm{rev}$ & $C \mathrm{~mm}$ & $\mathrm{R}_{\mathrm{a}} \mu \mathrm{m}$ & $\mathrm{HV} \mathrm{kgf} / \mathrm{mm}^{2}$ \\
\hline 1. & 175.00 & 0.16 & 1.00 & 1.083 & 316.8 \\
2. & 250.00 & 0.22 & 0.20 & 1.952 & 359.067 \\
3. & 175.00 & 0.16 & 0.60 & 1.083 & 322.533 \\
4. & 250.00 & 0.22 & 1.00 & 2.25 & 309.9 \\
5. & 175.00 & 0.16 & 0.60 & 1.026 & 321.833 \\
6. & 250.00 & 0.16 & 0.60 & 0.927 & 342.867 \\
7. & 250.00 & 0.10 & 0.20 & 0.583 & 332.367 \\
8. & 100.00 & 0.16 & 0.60 & 0.998 & 312.433 \\
9. & 250.00 & 0.10 & 1.00 & 0.474 & 331.767 \\
10. & 100.00 & 0.10 & 1.00 & 0.835 & 304.467 \\
11. & 175.00 & 0.16 & 0.60 & 1.068 & 314.567 \\
12. & 175.00 & 0.10 & 0.60 & 0.565 & 314.667 \\
13. & 100.00 & 0.22 & 1.00 & 2.244 & 286.833 \\
14. & 175.00 & 0.16 & 0.60 & 1.105 & 322.133 \\
15. & 175.00 & 0.16 & 0.60 & 1.081 & 305.6 \\
16. & 100.00 & 0.10 & 0.20 & 1.347 & 297.8 \\
17. & 100.00 & 0.22 & 0.20 & 1.768 & 325.367 \\
18. & 175.00 & 0.22 & 0.60 & 2.116 & 329.5 \\
19. & 175.00 & 0.16 & 0.60 & 1.104 & 315.133 \\
20. & 175.00 & 0.16 & 0.20 & 1.417 & 335.5 \\
\hline
\end{tabular}

Table 4. Results of ANOVA of surface roughness $\left(\mathrm{R}_{\mathrm{a}}\right)$.

\begin{tabular}{|c|c|c|c|c|c|}
\hline Source & Sum of squares & DF & Mean square & $\mathrm{F}$ Value & Prob $>$ F \\
\hline Model & 5.45 & 9 & 0.61 & 40.19 & $<0.0001$ \\
\hline$A$ & 0.10 & 1 & 0.10 & 6.71 & 0.0269 \\
\hline$B$ & 4.26 & 1 & 4.26 & 282.54 & $<0.0001$ \\
\hline$C$ & $3.276 \mathrm{E}-003$ & 1 & $3.276 \mathrm{E}-003$ & 0.22 & 0.6511 \\
\hline$A^{2}$ & 0.029 & 1 & 0.029 & 1.93 & 0.1949 \\
\hline$B^{2}$ & 0.21 & 1 & 0.21 & 13.81 & 0.0040 \\
\hline$C^{2}$ & 0.094 & 1 & 0.094 & 6.22 & 0.0318 \\
\hline$A B$ & 0.22 & 1 & 0.22 & 14.34 & 0.0036 \\
\hline$A C$ & $6.328 \mathrm{E}-003$ & 1 & $6.328 \mathrm{E}-003$ & 0.42 & 0.5316 \\
\hline$B C$ & 0.24 & 1 & 0.24 & 16.14 & 0.0024 \\
\hline Residual & 0.15 & 10 & 0.015 & & \\
\hline Lack of Fit & 0.15 & 5 & 0.029 & 34.53 & 0.0007 \\
\hline Pure Error & 4.243E-003 & 5 & 8.486E-004 & & \\
\hline Cor Total & 5.60 & 19 & & & \\
\hline \multicolumn{2}{|c|}{ Std. Dev. $=0.12$} & \multicolumn{4}{|c|}{ R-Squared $=0.9731$} \\
\hline \multicolumn{2}{|c|}{ Mean $=1.25$} & \multicolumn{4}{|c|}{ Adj R-Square = 0.9489} \\
\hline \multicolumn{2}{|c|}{ C.V. $=9.81$} & \multicolumn{4}{|c|}{ Pred R-Squared $=0.8788$} \\
\hline \multicolumn{2}{|c|}{$\mathrm{PRESS}=1.80$} & \multicolumn{4}{|c|}{ Adeq Precision $=22.838$} \\
\hline
\end{tabular}


Japan) was used to get surface roughness values. The microhardness tester (model: MitroWizard; make: Mitutoyo, Japan) was used to get microhardness values.

\section{Design of experiments}

In this study, in order to investigate the influence of cutting parameters on the response variables (surface roughness and microhardness) during dry hard turning, a sequential set of experimental runs was established using a Central Composite Design (CCD) of experiment as shown in table 3. Table 3 also shows the measured values of surface roughness (Ra) and microhardness (HV). Analysis of variance (ANOVA) was performed to identify factors which significantly affect the response variables. The parameter symbols typically used in ANOVA are described in (Montgomery 2010; Panneerselvam 2012; Krishnaiah 2012). For manufacturers to maximize their gains from utilizing finish hard turning, accurate predictive models for surface integrity must be constructed. In this study, response surface methodology (RSM) based experimental design was used since it offers more advantages than other design methods. RSM provides a systematic procedure to determine a relationship between independent input process parameters and output (process response). Many researchers have used RSM in their research pertaining to hard turning (Khamel et al 2012; Saini et al 2012; Suresh et al 2012; Aouici et al 2011; Bouacha et al

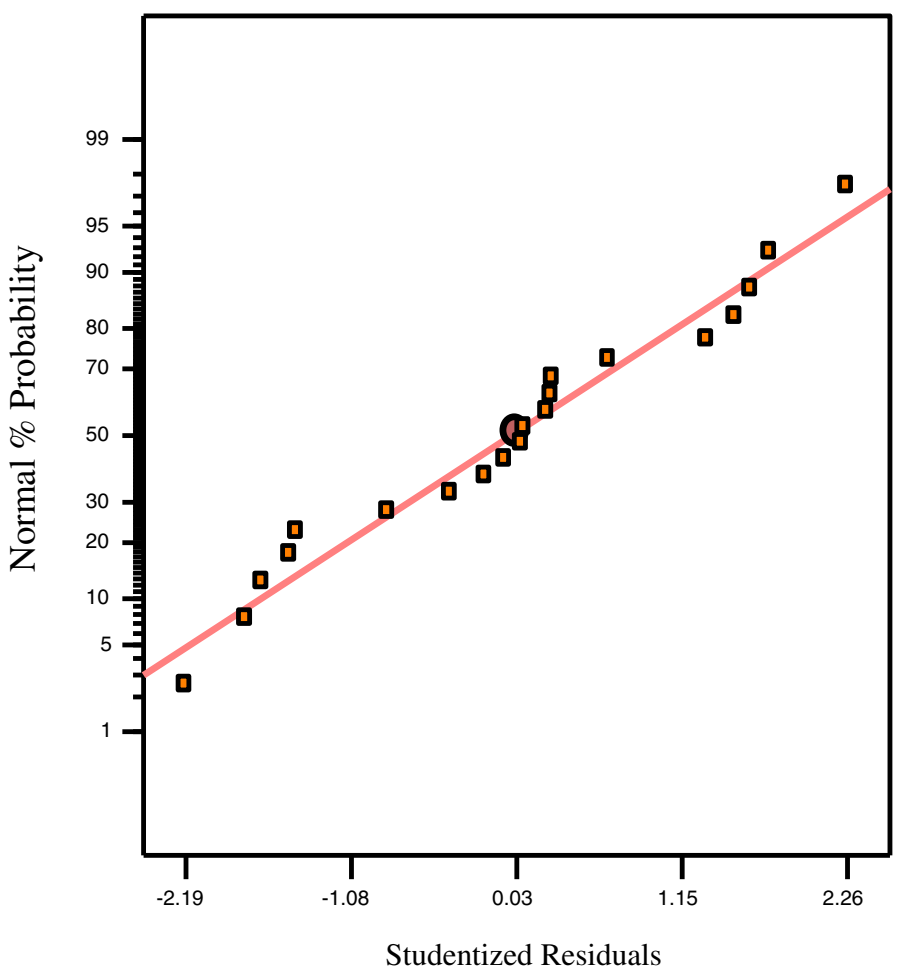

Figure 1. Normal plot of residual response. 
2010). The effect of various design parameters and the analysis with consideration of correlation between factors were studied through this design.

\section{Results and discussion}

The results of the present study are discussed in the following sections.

\subsection{Analysis of surface roughness}

Surface finish, by definition, is the allowable deviation from a perfectly flat surface that is made by some manufacturing process. Surface roughness $\left(R_{a}\right)$ is the most important variable of the surface finish, which is the arithmetic average of the absolute values of the roughness profile ordinates. The experimental data were analysed through Design-Expert software. The results of analysis of variance (ANOVA) of surface roughness $\left(\mathrm{R}_{\mathrm{a}}\right)$ in hard turning during dry condition are shown in table 4 which shows the degrees of freedom (DF), sum of squares (SS), mean squares (MS), F-values (F-VAL.) and probability (P-VAL.). It is clear from table 4 that feed rate $(B)$ has the most significant effect; while the cutting speed $(A)$, the quadratic value of feed rate $\left(B^{2}\right)$, the quadratic value of depth of cut $\left(C^{2}\right)$, the interaction between cutting speed and feed rate $(A B)$, and the interaction between feed rate and depth of cut $(B C)$ all have less significant effect, but the depth of cut $(C)$, the quadratic value of cutting speed $\left(A^{2}\right)$, and the interaction between

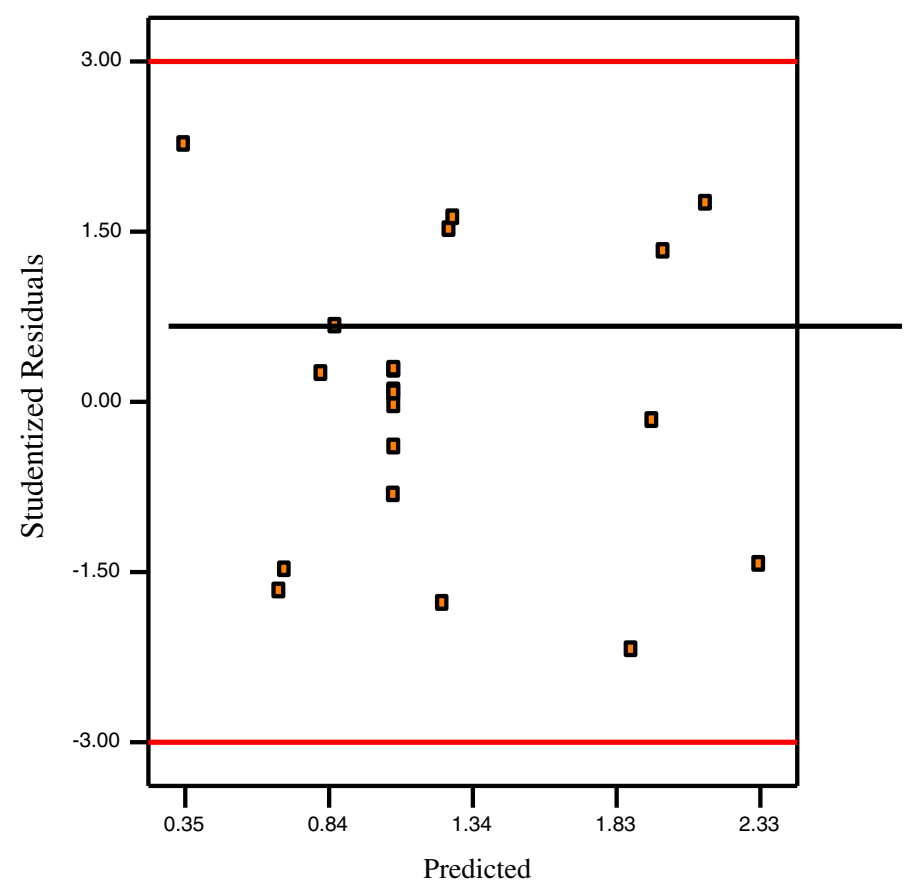

Figure 2. Plot of residuals vs. predicted response. 


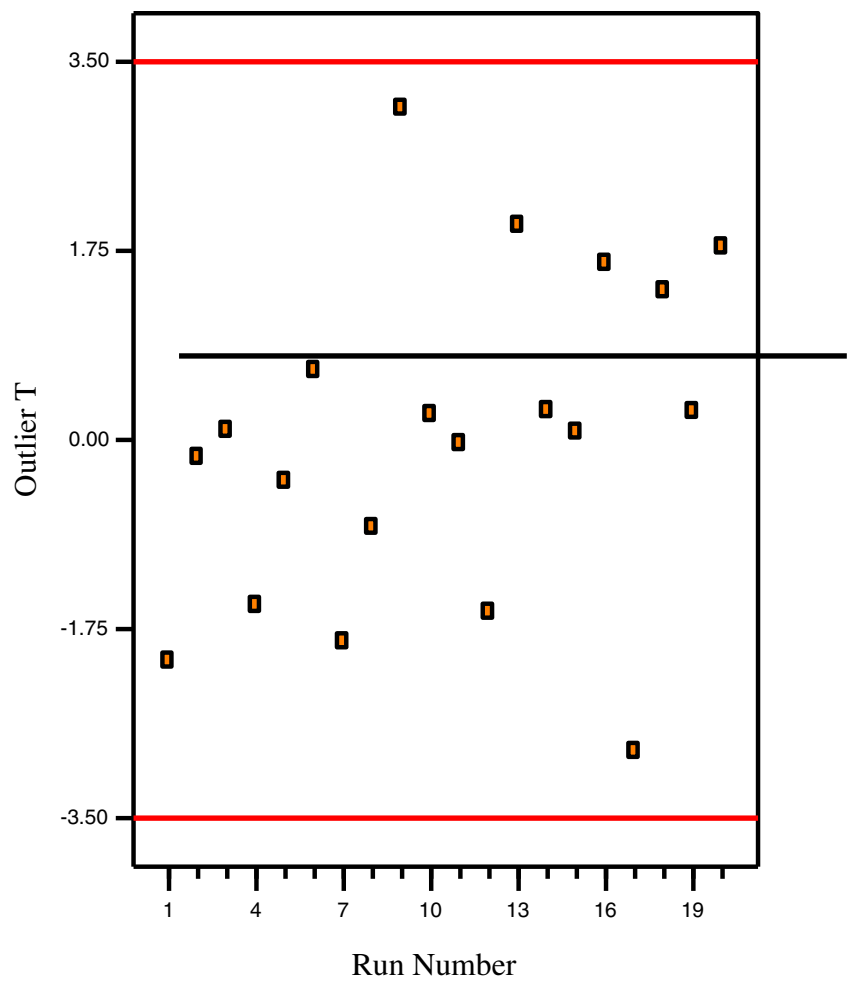

Figure 3. Plot of outlier $\mathrm{T}$ for $\mathrm{R}_{\mathrm{a}}$.

cutting speed and depth of cut $(A C)$ have no significant effect. It is clear from table 4 that the 'Pred R-Squared' of 0.8788 is in reasonable agreement with the 'Adj R-Squared' of 0.9489. 'Adeq Precision' measures the signal to noise ratio. A ratio greater than 4 is desirable and the

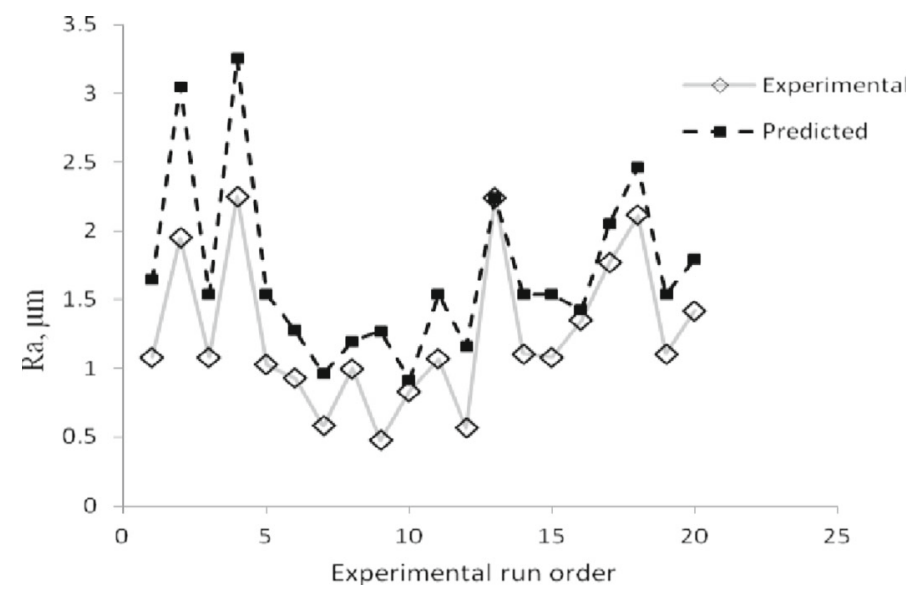

Figure 4. Comparison between measured and predicted values for surface roughness. 
DESIGN-EXPERT Plot

$\mathrm{Ra}$

Actual Factors

A: cutting speed $=175$.

$\mathrm{B}$ : feed rate $=0.160$

C: depth of cut $=0.600$

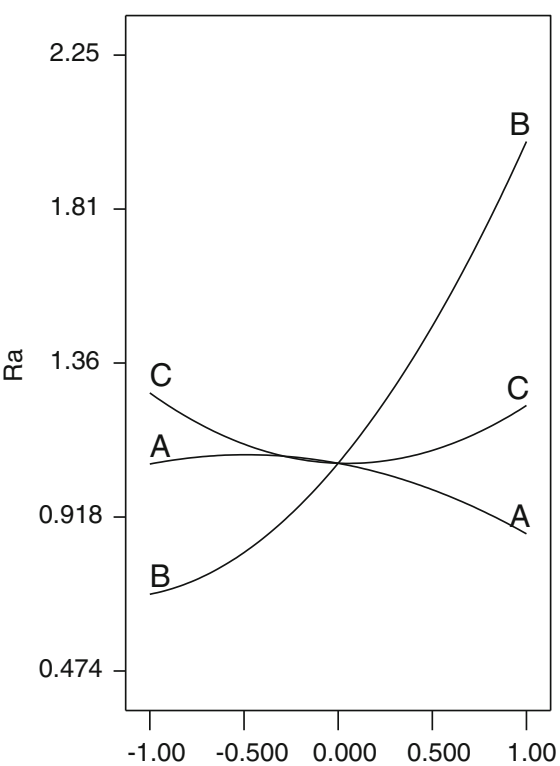

Deviation from Reference Point

Figure 5. Perturbation plot for surface roughness.

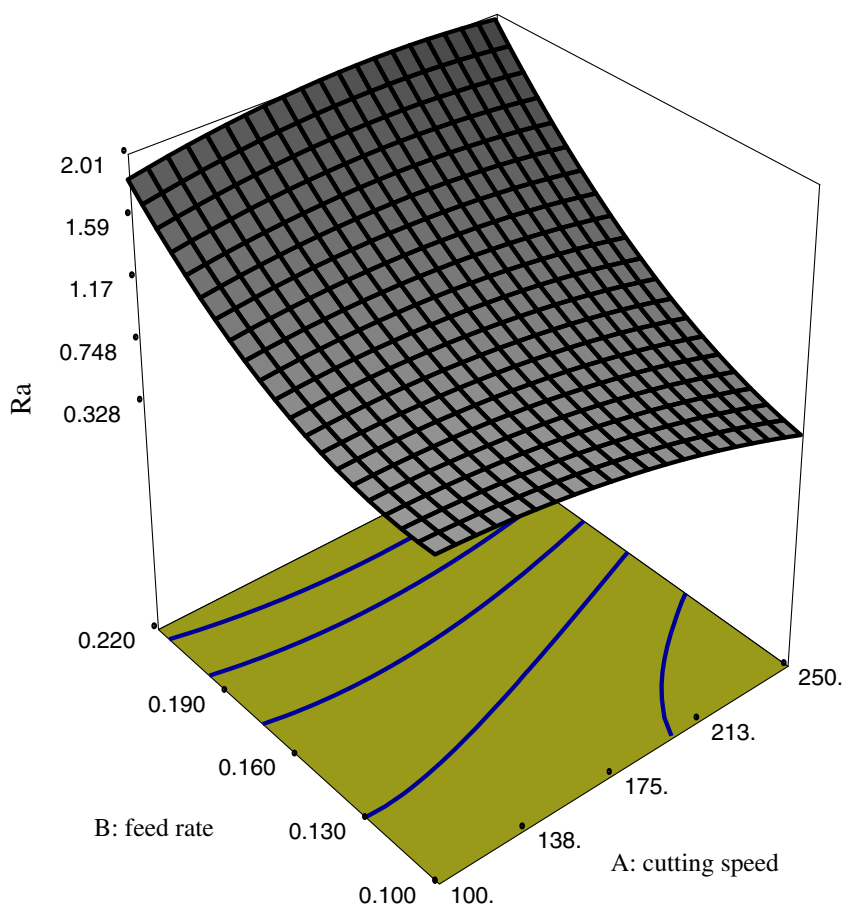

Figure 6. Effect of cutting speed and feed on $\mathrm{R}_{\mathrm{a}}$. 


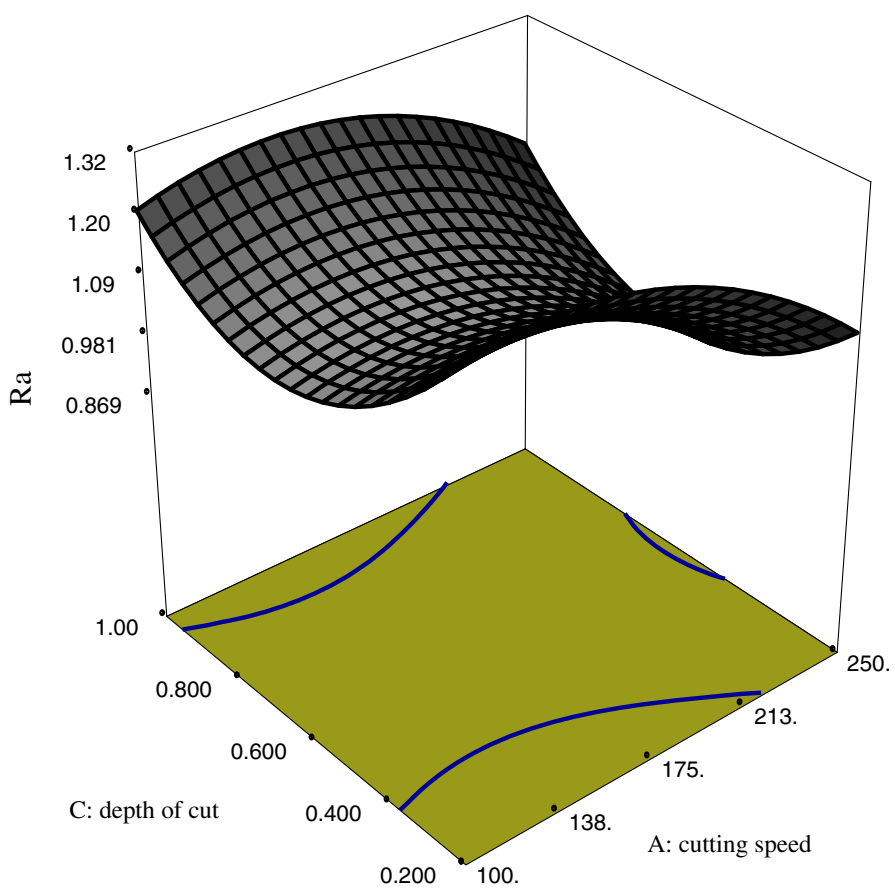

Figure 7. Effect of speed and depth of cut on $\mathrm{R}_{\mathrm{a}}$.

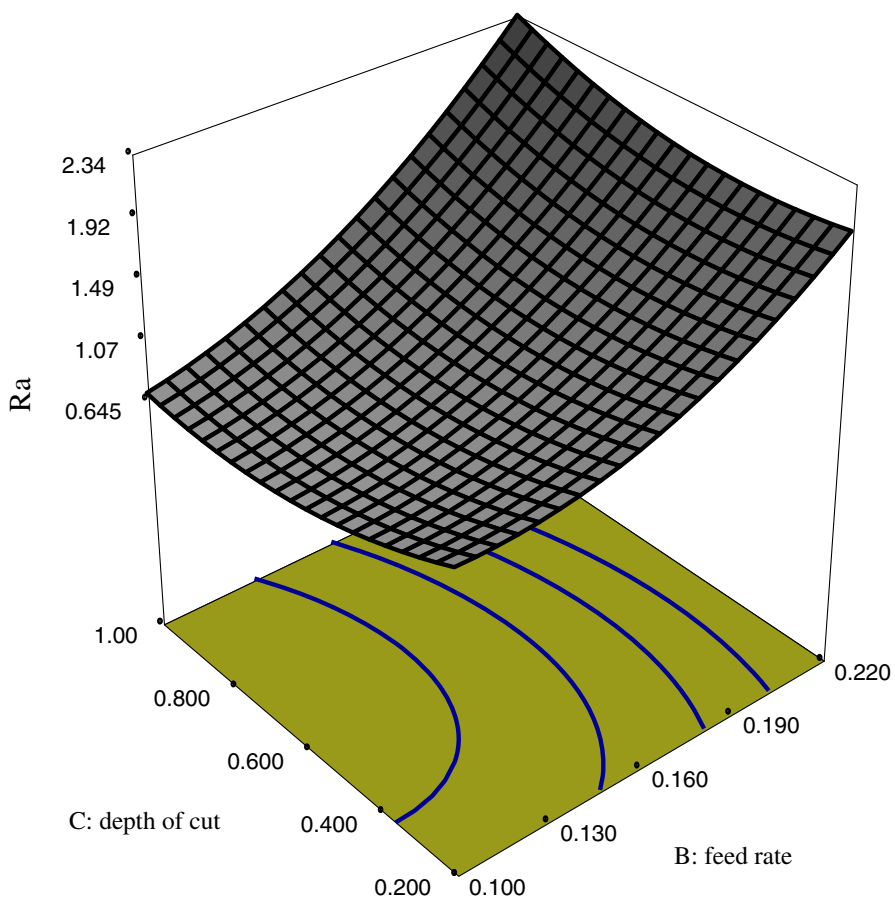

Figure 8. Effect of feed and depth of cut on $\mathrm{R}_{\mathrm{a}}$. 
Table 5. Results of ANOVA of microhardness (HV).

\begin{tabular}{|c|c|c|c|c|c|}
\hline Source & Sum of squares & DF & Mean square & F Value & Prob $>F$ \\
\hline Model & 4458.79 & 6 & 743.13 & 17.63 & $<0.0001$ \\
\hline$A$ & 2222.13 & 1 & 2222.13 & 52.72 & $<0.0001$ \\
\hline$B$ & 87.61 & 1 & 87.61 & 2.08 & 0.1731 \\
\hline$C$ & 1006.69 & 1 & 1006.69 & 23.88 & 0.0003 \\
\hline$A B$ & 3.25 & 1 & 3.25 & 0.077 & 0.7856 \\
\hline$A C$ & 40.05 & 1 & 40.05 & 0.95 & 0.3475 \\
\hline$B C$ & 1099.05 & 1 & 1099.05 & 26.07 & 0.0002 \\
\hline Residual & 548.00 & 13 & 42.15 & & \\
\hline Lack of Fit & 328.32 & 8 & 41.04 & 0.93 & 0.5575 \\
\hline Pure Error & 219.68 & 5 & 43.94 & & \\
\hline Cor Total & 5006.78 & 19 & & & \\
\hline \multicolumn{2}{|c|}{ Std. Dev. $=6.49$} & \multicolumn{4}{|c|}{$\mathrm{R}-$ Squared $=0.8905$} \\
\hline \multicolumn{2}{|c|}{ Mean = 320.06} & \multicolumn{4}{|c|}{ Adj R-Square $=0.8400$} \\
\hline \multicolumn{2}{|c|}{ C.V. $=2.03$} & \multicolumn{4}{|c|}{ Pred R-Squared $=0.7872$} \\
\hline \multicolumn{2}{|c|}{ PRESS $=1065.40$} & \multicolumn{4}{|c|}{ Adeq Precision $=18.757$} \\
\hline
\end{tabular}

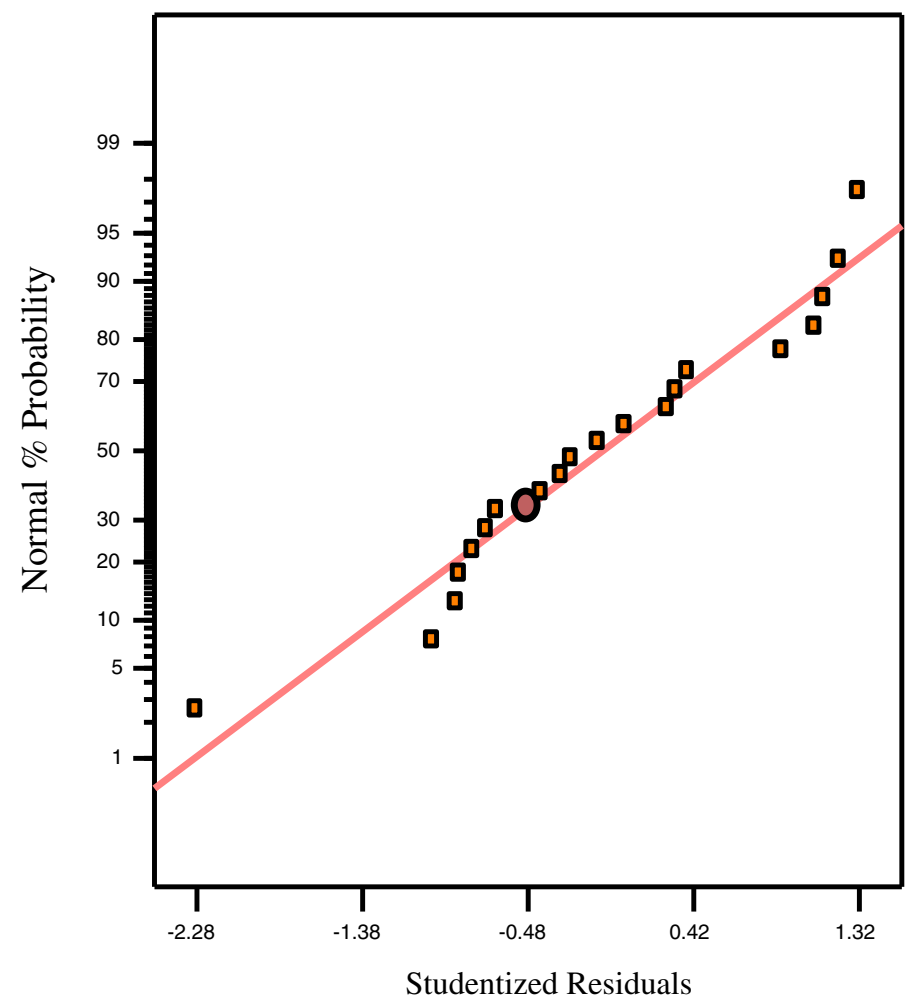

Figure 9. Normal plot of residual response. 
resulted ratio is 22.838 which indicates an adequate signal. This model can be used to navigate the design space.

The model equation in terms of actual factors for predicting $R_{a}$ is given by Eq. 1 :

$$
\begin{aligned}
& \mathrm{R}_{\mathrm{a}}=3.225-0.00135 \mathrm{~A}-24.331 \mathrm{~B}-2.756 \mathrm{C}-1.828 \mathrm{E}-005 A^{2}+76.426 B^{2 \breve{\mathrm{a}}}+ \\
& 1.153 C^{2} \breve{\mathrm{a}}+0.0365 A B+9.375 E-005 A C+7.265 B C
\end{aligned}
$$

Figure 1 presents the normal probability plot of the residuuals of $\mathrm{R}_{\mathrm{a}}$. This plot reveals that the residuals either fall on a straight line or are very close to the line implying that the errors are distributed normally. Figure 2 shows the standardized residuals with respect to the predicted values of surface roughness. The residuals do not show any obvious pattren and are distributed in both positive and negative directions. This implies that the model is adequate and there is no reason to suspect any violation of the independence or constant variance assumption. Figure 3 shows that all values of $R_{a}$ are within reasonable limit. The predicted values of the response factor i.e., $\mathrm{R}_{\mathrm{a}}$ from regression Eq. (1) corresponding to different machining parameters were obtained and subsequently compared with the corresponding experimental values. The comparison is depicted in figure 4. A perturbation plot was obtained to show and compare the effect of all machining parameters at the centre point on the surface roughness on a single plot. The perturbation plot is presented in figure 5 which reveals the following: (i) the surface roughness decreases with increase in the cutting speed $(A)$, (ii) the surface roughness increases significantly with increase in the feed rate $(B)$ and (iii) there is negligible effect of the depth of cut $(C)$

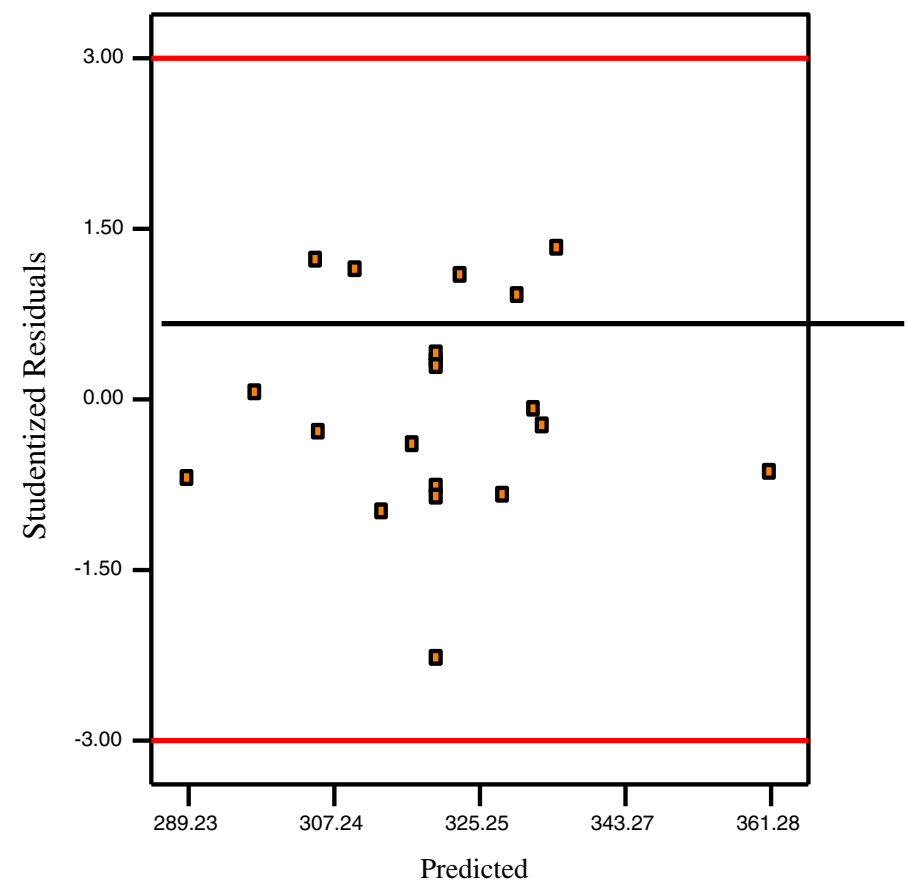

Figure 10. Plot of residuals vs. predicted response. 
on surface roughness. These results relate very well with the theory of metal cutting (Trent \& Wright 2000). At a particular value of the feed rate, an increase in the cutting speed reduces the advancement of the tool per unit time which consequently reduces the roughness. Similarly, an increase in the feed rate at a particular value of the cutting speed produces a contrary effect during turning and therefore roughness increases. The perturbation plot also reveals that the effect of the feed rate on surface roughness is less for small values of feed rate whereas it undergoes a steep rise for the larger values of the feed rate. This may be, apart from the reasons mentioned above, also due to the fact that at higher feed rates the material gets ploughed more than it undergoes shear. The depth of cut is indeed, representative of width of cut and it has less effect on surface roughness as suggested in the theory of metal machining (Trent \& Wright 2000; Goel et al 2012).

Figure 6 is constructed to illustrate the main effects of varying the two factors cutting speed $(A)$ and feed rate $(B)$ parameters on $\mathrm{R}_{\mathrm{a}}$, and keeping the depth of cut at constant level i.e., $0.6 \mathrm{~mm}$. It can be seen from figure 6 that higher cutting speed and lower feed rate results in lower $R_{a}$.

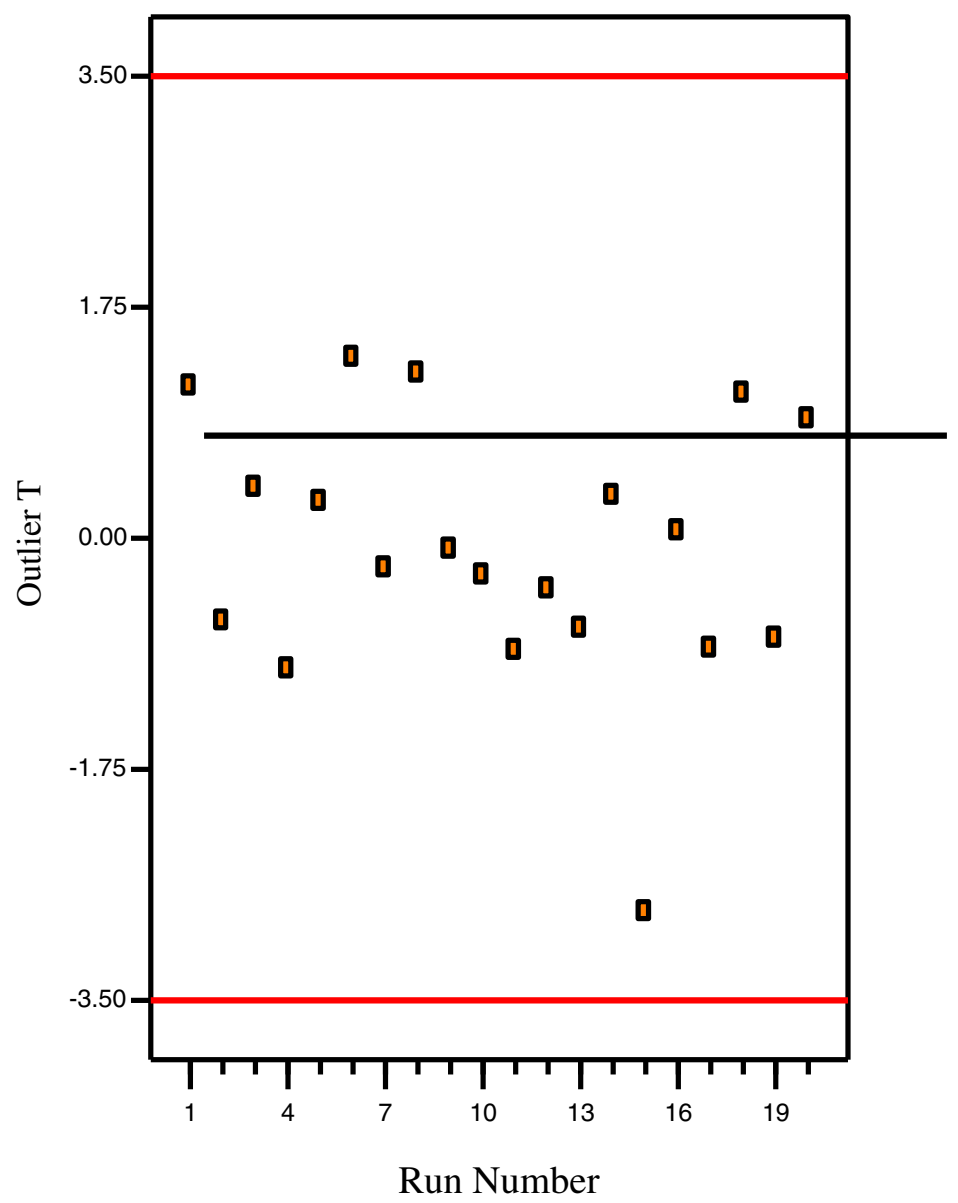

Figure 11. Plot of outlier T. 
Figure 7 illustrates the main effects of varying the two factors cutting speed $(A)$ and depth of cut $(C)$ on $\mathrm{R}_{\mathrm{a}}$, keeping the feed rate at constant level i.e., $0.16 \mathrm{~mm} / \mathrm{rev}$. Figure 7 reveals that the best value of $R_{a}$ is achieved at the middle level of cutting speed and depth of cut combinations, whereas high value of $\mathrm{R}_{\mathrm{a}}$ is obtained at either the highest or the lowest values of cutting speed and depth of cut combinations. Figure 8 shows the effect of feed rate $(B)$ and depth of cut $(C)$ on $\mathrm{R}_{\mathrm{a}}$, keeping the cutting speed at constant level i.e., $175 \mathrm{~m} / \mathrm{min}$. It can be observed from figure 8 that a combination of lower feed rate and lower depth of cut results in lower $\mathrm{R}_{\mathrm{a}}$.

\subsection{Analysis of microhardness}

The results of analysis of variance (ANOVA) of microhardness (HV) are shown in table 5. It is clear from table 5 that cutting speed $(A)$ has the most significant effect on $\mathrm{HV}$; while factor $C$, interaction $B C$ have less significant effect, but factor $B$, interaction $A B$, and interaction $A C$ have no significant effect. It is also clear from table 5 that the 'Pred R-Squared' of 0.7872 is in reasonable agreement with the 'Adj R-Squared' of 0.8400. 'Adeq Precision' measures the signal to noise ratio. A ratio greater than 4 is desirable and the resulted ratio is 18.757 which indicates an adequate signal. This model can be used to navigate the design space.

The model equation in terms of actual factors for predicting $\mathrm{HV}$ is given by Eq. 2:

$$
\begin{aligned}
\mathrm{HV}= & +233.74928+0.26617 A+367.14833 B+66.10858 C-0.14167 A B \\
& -0.074583 A C-488.37500 B C .
\end{aligned}
$$

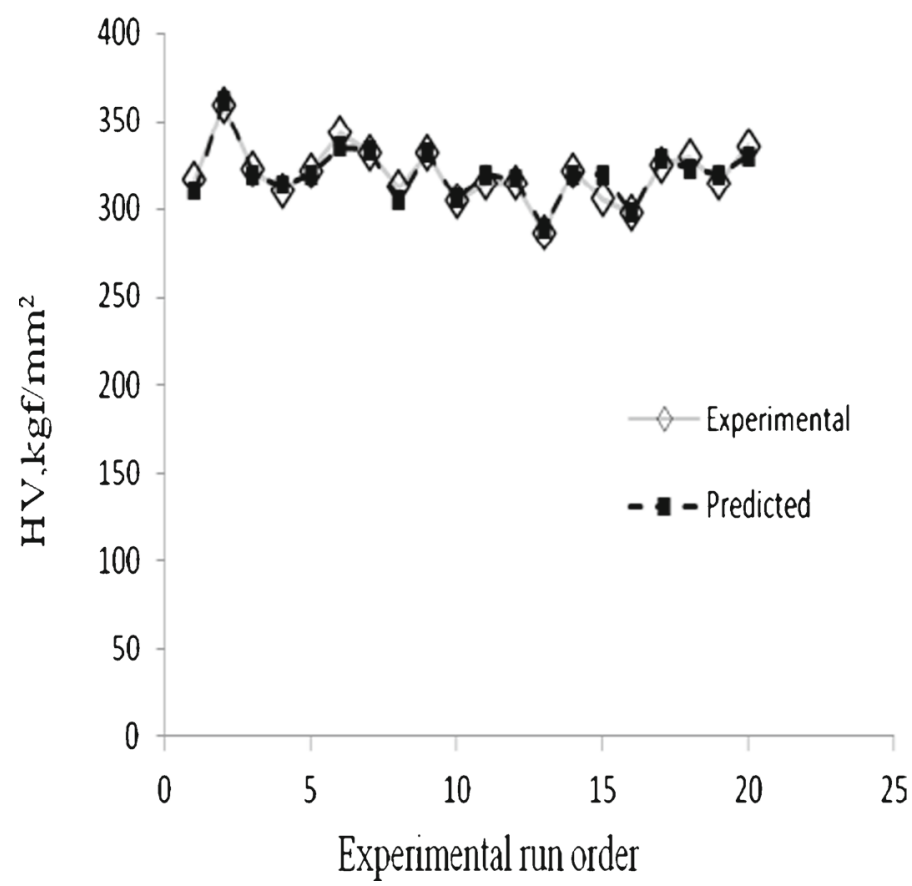

Figure 12. Comparison between measured and predicted values for microhardness. 
Figure 9 presents the normal probability plot of the residuuals of (HV). This plot reveals that the residuals either fall on a straight line or are very close to the line implying that the errors are distributed normally. Figure 10 shows that microhardness values are normaly and independantly distributed. Figure 11 shows that all values of $\mathrm{HV}$ are within reasonable limit. Using regression Eq. (2), the predicted values of the response factor i.e., HV corresponding to different machining parameters were obtained and these values were compared with the corresponding experimental values. The comparison between the predicted and the corresponding experimental values is shown in figure 12. In order to comprehend the effect of all machining parameters on the microhardness, a perturbation plot was obtained as presented in figure 13 which exhibits: (i) significant increase in the microhardness with increase in the cutting speed $(A)$, (ii) negligible effect of the feed rate $(B)$ on the microhardness and (iii) significant reduction in the microhardness with increase in the depth of cut $(C)$. These results agree well with the theory of metal cutting. An increase in the cutting speed significantly increases the rate of shear and a consequent increase in work-hardening of the machined surface. Apart from the work-hardening, the strain rate strengthening is also expected to have contributed to increase in surface hardening. The turning depth of cut would have resulted in high volume of material being sheared per unit time resulting in an increase in machining heat. The increased amount of heat would have relieved the residual stress consequently causing hardness to drop with

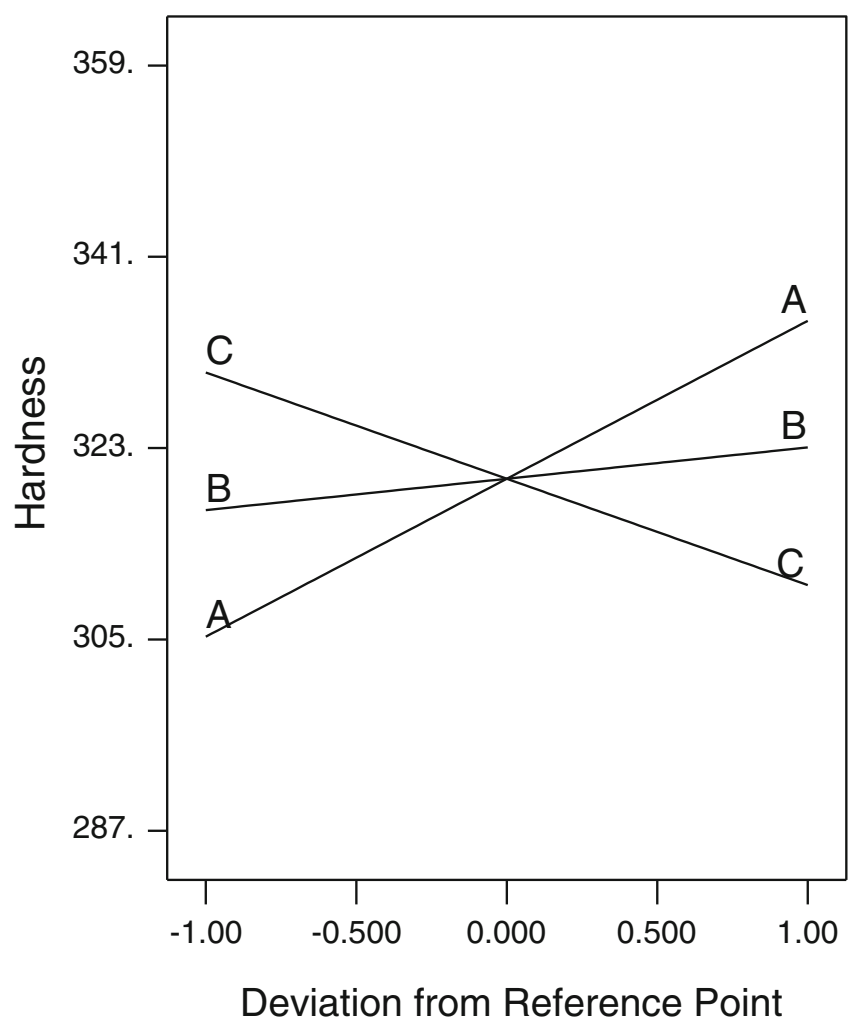

Figure 13. Perturbation plot for microhardness. 
an increase in depth of cut (Trent \& Wright 2000). Figure 14 illustrates the main effects of varying the two factors cutting speed $(A)$ and feed rate $(B)$ on microhardness (HV) while keeping the depth of cut $(C)$ at constant level i.e., $0.6 \mathrm{~mm}$. It can be seen from figure 14 that the lower cutting speed and lower feed rate results in lower hardness. Figure 15 reveals the effect of cutting speed and depth of cut on HV and keeping the feed rate $(B)$ at constant level i.e., $0.16 \mathrm{~mm} / \mathrm{rev}$. It can be seen from Figure 15 that lower cutting speed and higher depth of cut results in lower hardness. Figure 16 illustrates the main effects of varying feed rate and depth of cut on microhardness while keeping the cutting speed at constant level i.e., 175. It can be seen from figure 16 that the best value of HV is achieved either at the highest levels of feed rate and depth of cut combinations or the lowest levels of feed rate and depth of cut combinations.

\subsection{Response optimization}

One of the main goals for the experiment is to help investigate optimal values of cutting parameters in order to obtain the desired value of the machined surface roughness and microhardness during the dry hard turning process. Figure 17 shows the ramp function gragh for the optimum value of the cutting parameters to obtain minimum values of surface roughness and target values of microhardness for the machined surface. It may be mentioned that target value of hardness is

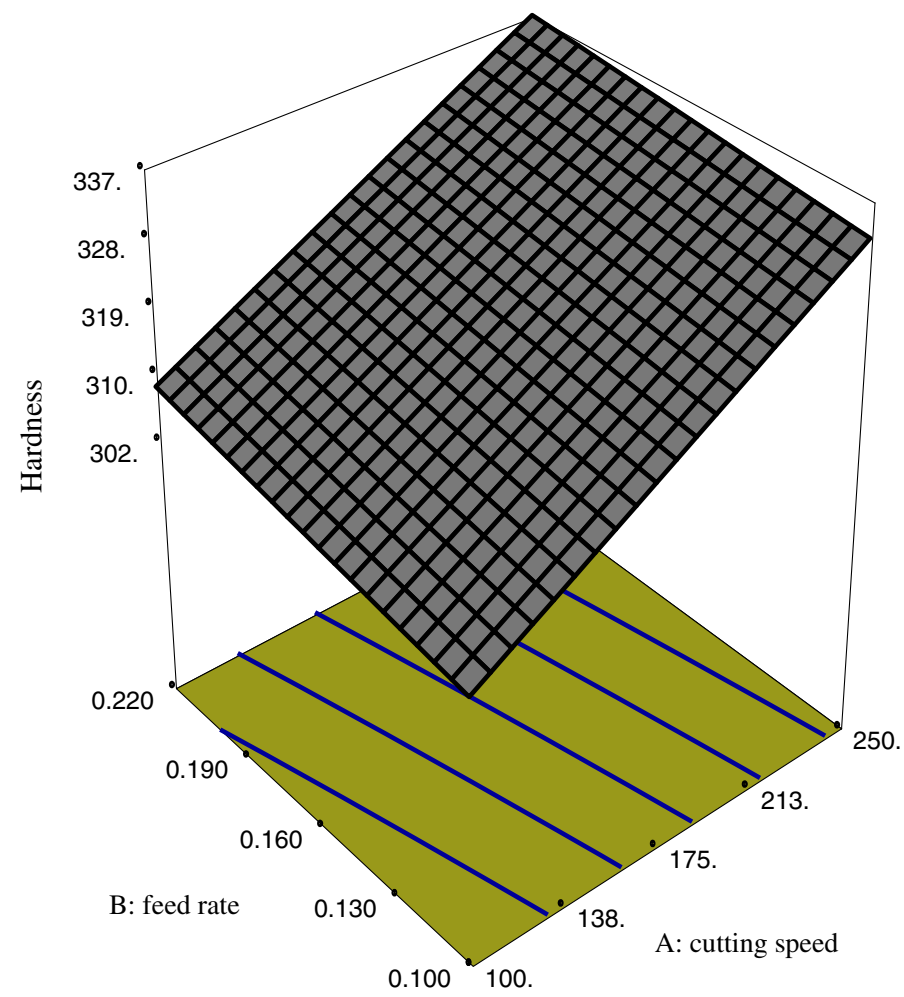

Figure 14. Effect of cutting speed and feed rate on HV. 


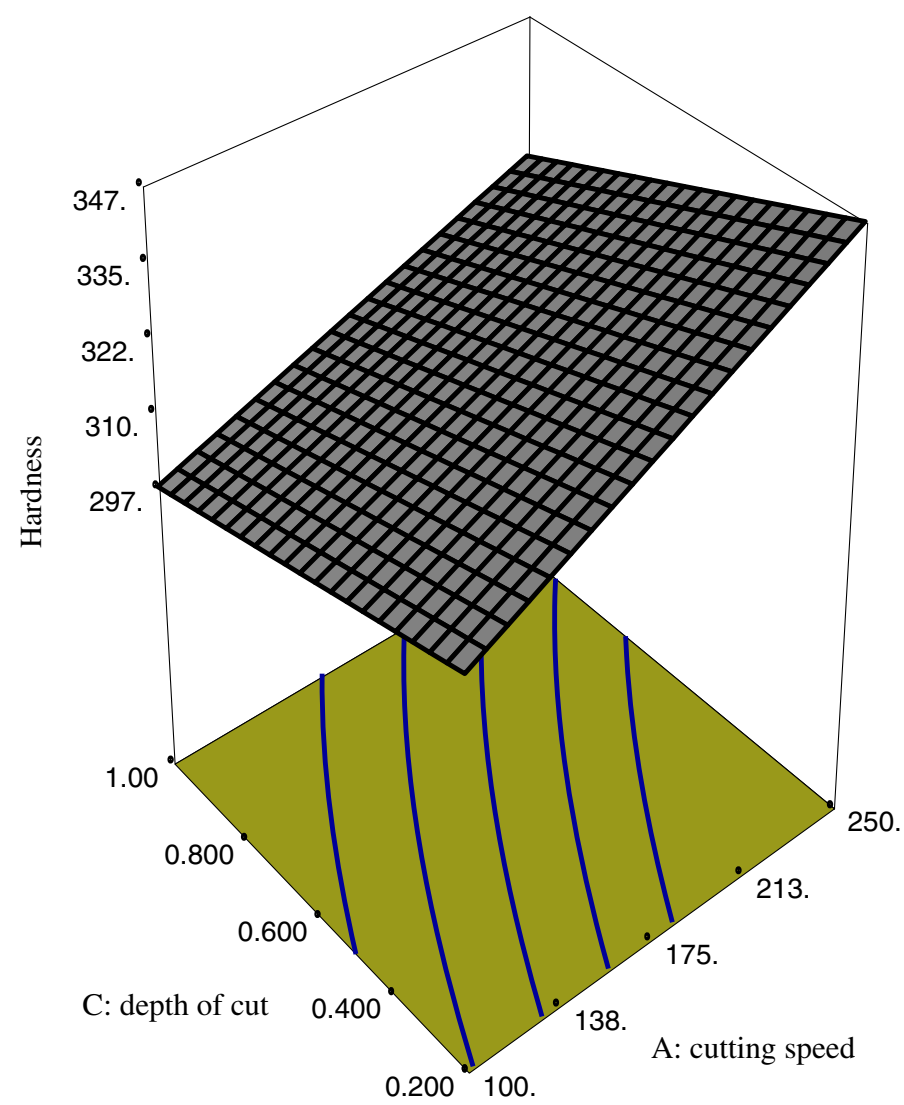

Figure 15. Effect of speed and depth of cut on HV.

same as the base hardness which is equal to $352.4 \mathrm{kgf} / \mathrm{mm}^{2}$. It can be seen from figure 17 that the optimal values of surface ingirity variables $\left(\mathrm{R}_{\mathrm{a}}\right.$, and $\left.\mathrm{HV}\right)$ were $0.4740 \mu \mathrm{m}$, and $334.4 \mathrm{kgf} / \mathrm{mm}^{2}$, respectivly at cutting speed $250 \mathrm{~m} / \mathrm{min}$, feed rate $0.1164 \mathrm{~mm} / \mathrm{rev}(\approx 0.12 \mathrm{~mm} / \mathrm{rev})$, and depth of cut $0.4773 \mathrm{~mm}(\approx 0.48 \mathrm{~mm})$ as optimum value of cutting parameters. The numerical optimization found a point that maximizes the desirability value as 0.852 which corresponds to the minimum values of surface roughness and target values of microhardness.

In order to validate the optimal parameters, an experimental run was made in which cutting speed, feed rate and depth of cut were set at $250 \mathrm{~m} / \mathrm{min}, 0.12 \mathrm{~mm} / \mathrm{rev}$ and $0.48 \mathrm{~mm}$, respectively. Subsequently, surface roughness and microhardness of the machined component were measured as per the procedure outlined in the above sections. The surface roughness and microhardness values were found to be $0.592 \mu \mathrm{m}$ and $338.536 \mathrm{kgf} / \mathrm{mm}^{2}$, respectively. When the experimental values of surface roughness and microhardness are compared with those of optimum values, it is found that these values are close to each other. Thus, it verifies the optimum setting of machining parameters and optimum values of response variables as well. 


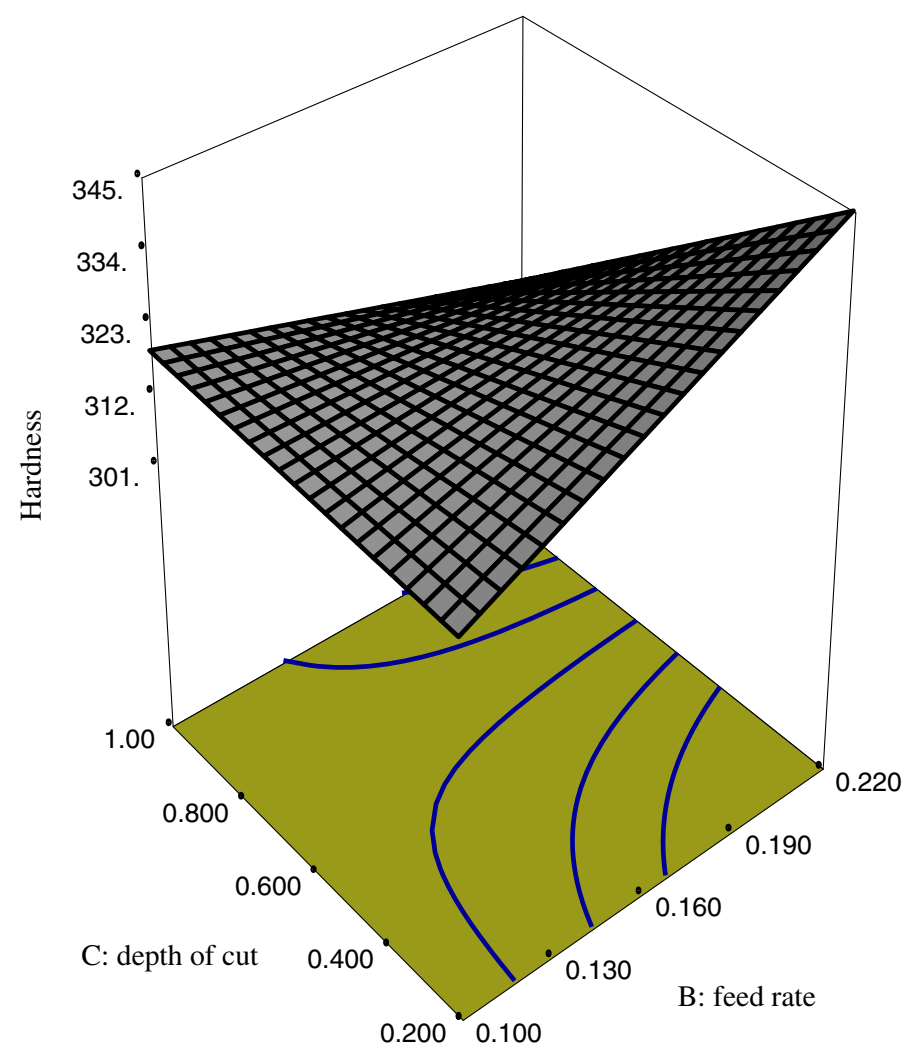

Figure 16. Effect of feed rate and depth of cut on HV.
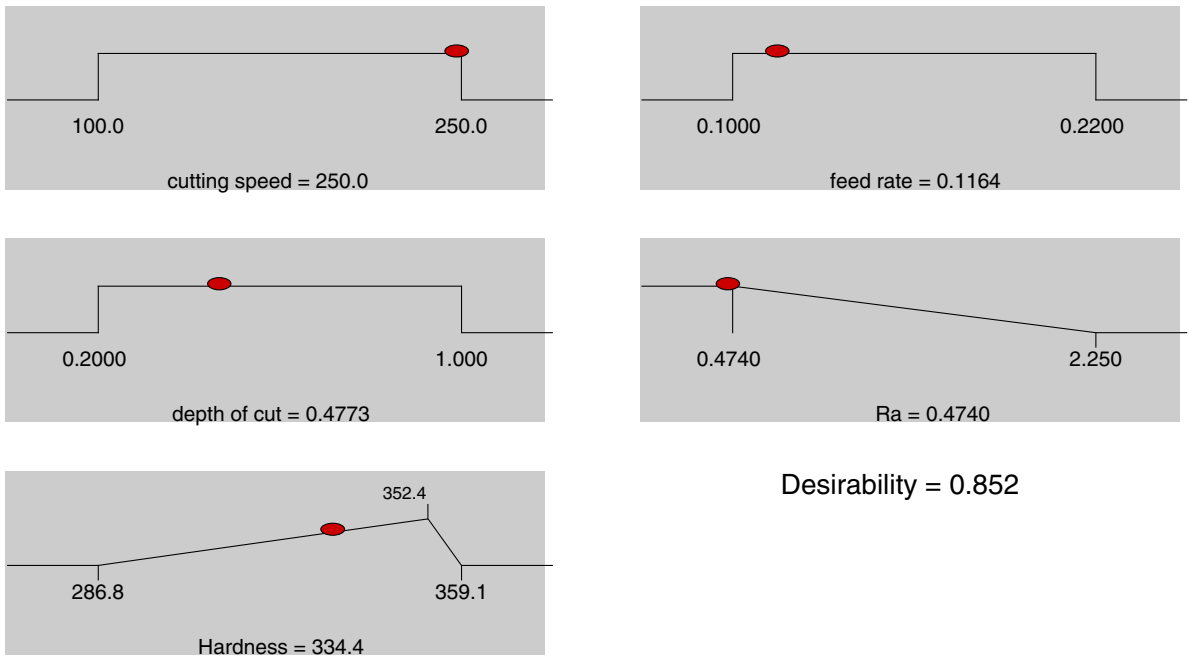

Desirability $=0.852$

Figure 17. Rump function of cutting parameters for surface roughness and microhardness. 


\section{Conclusion}

This paper presented the effect of the cutting parameters (cutting speed, feed rate, and depth of cut) on the surface roughness and microhardness during dry hard turning of AISI 52100 alloy steel using carbide coated insert. The feed rate is found to have statistically the most significant effect on surface roughness while the cutting speed and depth of cut have a very small effect on surface roughness. The cutting speed is observed to have the most significant effect on microhardness. The depth of cut has less significant effect and the feed rate has a very small effect on microhardness. Optimum values of machining parameters have been computed using RSM design. The results also indicated that RSM is very useful technique to model and to create equations for forecasting and optimizing with reasonably minimum possible experiments. The optimization results suggest that good surface integrity can be achieved when feed rate and depth of cut are set nearer to its low level of the experimental range $(0.1 \mathrm{~mm} / \mathrm{rev}$ and $0.2 \mathrm{~mm})$ respectively, whereas cutting speed at high level of the experimental range $(250 \mathrm{~m} / \mathrm{min})$.

\section{Acknowledgements}

The authors thank Jamia Millia Islamia University, New Delhi, India and Indian Institute of Technology (IIT) Delhi, New Delhi, India for providing facilities for conducting experiments and measurements which are reported in this paper and also Diyala University, Diyala, Iraq for providing financial assistance.

\section{References}

Aslan E, Camuscu N and Birgoren B 2007 Design optimization of cutting parameters when turning hardened AISI 4140 steel (63 HRC) with Al2O3 + TiCN mixed ceramic tool. Mater. Des. 28: 16181622

Aouici H, Yallese M A, Fnides B, Chaoui K and Mabrouki T 2011 Modeling and optimization of hard turning of X38CrMoV5-1 steel with CBN tool Machining parameters effects on flank wear and surface roughness. J. Mech. Sci. Technol. 25: 2843-2851

Benga G C and Abrao A M 2003 Turning of hardened 100Cr6 bearing steel with ceramic and PCBN cutting tools. J. Mater. Process. Technol. 143-144: 237-241

Bouacha K, Yallese M A, Mabrouki T and Rigal J-F 2010 Statistical analysis of surface roughness and cutting forces using response surface methodology in hard turning of AISI 52100 bearing steel with CBN tool. Int. J. Refract. Metals Hard Mater. 28: 349-361

Davim J P and Figueira L 2007 Machinability evaluation in hard turning of cold work tool steel (D2) with ceramic tools using statistical techniques. Mater. Des. 28: 1186-1191

Dhar N R, Paul S and Chattopadhyay A B 2002 The influence of cryogenic cooling on tool wear, dimensional accuracy and surface finish in turning AISI 1040 and E4340C steels. Wear 249: 932942

Diniz A E and Oliveira A J 2004 Optimizing the use of dry cutting in rough turning steel operations. Int. J. Mach. Tools Manufact. 44: 1061-1067

Diniz A E, Ferreira J R and Filho F T 2003 Influence of refrigeration/lubrication condition on SAE 52100 hardened steel turning at several cutting speeds. Int. J. Mach. Tools Manuf. 43: 317-326

Ezugwu E O, Silva R B, Da Bonney J and Machado A R 2005 Evaluation of the performance of CBN tools when turning Ti-6Al-4V alloy with high pressure coolant supplies. Int. J. Mach. Tools Manufact. 45: $1009-1014$ 
Gaitonde V N, Karnik S R, Figueira L and Davim J P 2009 Machinability investigations in hard turning of AISI D2 cold work tool steel with conventional and wiper ceramic inserts. Int. J. Refract. Metals Hard Mater. 27: 754-763

Goel P, Khan Z A, Siddiquee A N and Gupta R K 2012 Influence of Slab Milling Process Parameters on Surface Integrity of HSLA: A Multi-performance characteristics optimization. Int. J. Adv. Manufact. Technol. 61: 859-871

Grzesik W and Wanat T 2006 Surface finish generated in hard turning of quenched alloy steel parts using conventional and wiper ceramic inserts. Int. J. Mach. Tools Manufact. 46: 1988-1995

Isik Y 2007 Investigating the machinability of tool steels in turning operations. Mater. Des. 28: 1417-1424

Khamel S, Ouelaa N and Bouacha K 2012 Analysis and prediction of tool wear, surface roughness and cutting forces in hard turning with CBN tool. J. Mech. Sci. Technol. 26: 3605-3616

Khan M M A, Mithu M A H and Dhar N R 2009 Effects of minimum quantity lubrication on turning AISI 9310 alloy steel using vegetable oil-based cutting fluid. J. Mater. Process. Technol. 209: 5573-5583

Krishna P V, Srikant R R and Rao D N 2010 Experimental investigation on the performance of nanoboric acid suspensions in SAE-40 and coconut oil during turning of AISI 1040 steel. Int. J. Mach. Tools Manufact. 50: 911-916

Krishnaiah K 2012 Applied design of experiments and Taguchi methods, New Delhi, A. K. Ghosh, PHI Learning Private Limited

Kumar A S and Durai A R 2003 Machinability of hardened steel using alumina based ceramic cutting tools. Int. J. Refract. Metals Hard Mater. 21: 109-117

Kumar C H R V and Ramamoorthy B 2007 Performance of coated tools during hard turning under minimum fluid application. J. Mater. Process. Technol. 185: 210-216

Manna A and Salodkar S 2008 Optimization of machining conditions for effective turning of E0300 alloy steel. J. Mater. Process. Technol. 203: 147-153

Montgomery D C 2010 Design and analysis of experiments. 7th edition, Delhi, John Wiley and Sons

Morea A S, Jiang W, Brown W D and Malshe A P 2006 Tool wear and machining performance of cBNTiN coated carbide inserts and PCBN compact inserts in turning AISI 4340 hardened steel. J. Mater. Process. Technol. 180: 253-262

Paiva A P, Paiva E J, Ferreira J R, Balestrassi P P and Costa S C 2009 A multivariate mean square error optimization of AISI 52100 hardened steel turning. Int. J. Adv. Manuf. Technol. 43: 631-643

Panneerselvam R 2012 Design and analysis of experiments, New Delhi, A. K. Ghosh, PHI Learning Private Limited

Ramesh A, Melkote S N, Allard L F and Riester L 2005 Analysis of white layers formed in hard turning of AISI 52100 steel. Mater. Sci. Eng. 390: 88-97

Risbood K A, Dixit U S and Sahasrabudhe A D 2003 Prediction of surface roughness and dimensional deviation by measuring cutting forces and vibrations in turning process. J. Mater. Process. Technol. 132: 203-214

Sahin Y and Motorcu A R 2008 Surface roughness model in machining hardened steel with cubic boron nitride cutting tool. Int. J. Refract. Metals Hard Mater. 26: 84-90

Saini S, Ahuja I S and Sharma V S 2012 Influence of cutting parameters on tool wear and surface roughness in hard turning of AISI H11 tool steel using ceramic tools. Int. J. Precis. Eng. Manufact. 13: 1295-1302

Sharma V S, Dhiman S, Sehgal R and Sharma S K 2008 Estimation of cutting forces and surface roughness for hard turning using neural networks. J. Intell. Manuf. 19: 473-483

Suresh R, Basavarajappa S, Gaitonde V N and Samuel G L 2012 Machinability investigations on hardened AISI 4340 steel using coated carbide insert. Int. J. Refract. Metals Hard Mater. 33: 75-86

Thakur D G, Ramamoorthy B and Vijayaraghavan L 2009 Study on the machinability characteristics of superalloy Inconel 718 during high speed turning. Mater. Des. 30: 1718-1725

Thiele J D and Melkote S N 1999 Effect of cutting edge geometry and workpiece hardness on surface generation in the finish hard turning of AISI 52100 steel. J. Mater. Process. Technol. 94: 216-226

Trent E M and Wright P K 2000 Metal Cutting, Fourth Edition, Butterworth-Heinemann, Boston, U.S.A 
Tzeng C-J, Lin Y-H, Yang Y-K and Jeng M-C 2009 Optimization of turning operations with multiple performance characteristics using the Taguchi method and Grey relational analysis. J. Mater. Process. Technol. 209: 2753-2759

Umbrello D, Ambrogio G, Filice L and Shivpuri R 2008 A hybrid finite element method-artificial neural network approach for predicting residual stresses and the optimal cutting conditions during hard turning of AISI 52100 bearing steel. Mater. Des. 29: 873-883 